\title{
Usulan perancangan perbaikan stasiun kerja dengan analisis peta kerja dan kebutuhan ruang untuk peningkatan produktivitas
}

\author{
Armijal $^{1) *}$, Muhammad Firdaus ${ }^{2)}$ \\ ${ }^{1}$ Teknik Industri Universitas Andalas, Kampus Limau Manis, Padang, Indonesia. \\ ${ }^{2}$ PT Data Script Indonesia, Jl. Raden Saleh, Medan, Indonesia. \\ armijal@eng.unand.ac.id *; Mfirdaus@gmail.com
}

\begin{abstract}
ABSTRAK
CV. Raya Sport merupakan UKM yang bergerak di bidang konfeksi yang menghasilkan pakaian olahraga. UKM ini memiliki beberapa stasiun kerja, yang salah satunya adalah stasiun kerja penyablonan yang meliputi kegiatan penyablonan dan penjemuran. Pada stasiun ini terdapat kegiatan-kegiatan non-produktif (waste) berupa kegiatan berjalan secara overlapping dan terus menerus dari meja sablon ke area penjemuran pada saat menjemur kaos yang telah disablon serta kegiatan penataan ulang (rework) aktivitas penjemuran. Aktivitas-aktivitas nonproduktif ini menyebabkan waktu pengerjaan pada stasiun penyablonan menjadi lebih lama dan tidak produktif. Selain itu, terbatasnya area penjemuran juga menurunkan produktivitas karena operator harus menata jemuran di lantai dan berpotensi menurunkan kualitas sablon. Penelitian ini bertujuan untuk mengevaluasi dan mengusulkan perancangan perbaikan proses dan metode kerja pada stasiun penyablonan menggunakan analisis peta kerja dan kebutuhan ruang (space requirement). Hasil analisis menggunakan PTKTK, FPC dan analisis space requirement diketahui bahwa tangan kiri dan tangan kanan tidak bekerja secara seimbang, waktu pengerjaan yang lama dan tidak produktif, serta kebutuhan ruang (space) yang tidak memadai. Oleh karena itu diperlukan pengkajian dan evaluasi fasilitas kerja dan metode kerja di lantai produksi dengan mempertimbangkan faktor ergonomi, efisiensi dan produktivitas. Usulan perbaikan perancangan stasiun kerja yang diusulkan adalah berupa desain alat bantu penjemuran yang terdiri atas tiang jemuran, rel yang bisa digeser, serta pengait.
\end{abstract}

Kata kunci: Produktivitas Kerja, Perbaikan Stasiun Kerja, Keunggulan Kompetitif, Industri Kecil dan Menengah, Aktivitas penjemuran

\section{ABSTRACT}

$C V$. Raya Sport is an SME engaged in the confectionery that produces sportswear. This SME has several work stations, one of which is a printing work station which covers printing and drying activities. This station experiences poor productivity performance due to the existence and recurring of non-productive activities. This non-productive activity is in the form of recurring, back and forth movement of operator from the printing desk to the drying and rework activities. These non-productive activities result in longer processing time at the drying station. In addition, the limited drying area also reduces productivity because operators needs to arrange and rearrange clothes when drying them on the floor. This research aims to evaluate and propose an improved process and work method at printing station using operation chart and space requirement analysis. Using PTKTK, FPC and space requirements analysis, it's found that the left and right hands do not work in a balanced manner, the processing time is long and unproductive, and the space requirements are inadequate. Therefore, it is necessary to study and evaluate working facilities and methods on the production floor by considering ergonomics, efficiency and productivity factors. The proposed work improvement is in the form of a drying tool design consisting of a clothesline pole, a sliding rail, and a hook.

Keyword: Work productivity, workstation improvement, competitive advantage, small \& medium enterprises, drying activities.

diunggah: November 2021, direvisi: Desember 2021, diterima: Desember 2021, dipublikasi: Desember 2021 Copyright (c) 2021 Armijal, Muhammad Firdaus

This is an open access article under the CC-BY license 


\section{PENDAHULUAN}

Perkembangan dan persaingan industri yang semakin pesat memaksa perusahaan memiliki keunggulan kompetitif guna mampu bertahan/memenangkan persaingan (Rosa, 2003). Untuk mencapai keunggulan tersebut, diantaranya dilakukan dengan meningkatkan produktivitas. Supriyanto (2015) mendefinisikan produktivitas sebagai rasio/perbandingan antara hasil yang diharapkan (output) dengan usaha yang diberikan (input) dalam mencapai tujuan. Wahyono (2006) berpendapat bahwa sebuah perusahaan bisa mencapai produktivitas tinggi apabila mampu mengefisiensikan sumber masukan (input) baik berupa modal, material, teknologi, informasi dan lainnya dalam berproduksi. Input dapat berupa, jumlah tenaga kerja, waktu penyelesaian produk, peralatan fasilitas kerja, bahan baku dan sebagainya (Indrajaya, 2019). Penting bagi perusahaan untuk mengefisiensikan input dan proses guna memperoleh produktivitas yang tinggi, yang salah satunya bisa diperoleh dengan melakukan perancangan stasiun kerja sedemikian sehingga mampu mengeliminasi kegiatan-kegiatan non-produktif.

CV. Raya Sport merupakan industri yang bergerak di bidang konveksi yang menghasilkan produk berupa pakaian olahraga dengan proses produksi diantaranya adalah proses pembuatan pola, pemotongan, penjahitan, penyablonan dan pengepakan. Penelitian ini difokuskan pada stasiun penyablonan yang terdiri dari kegiatan penyablonan dan menjemur kaos yang telah di sablon. Alasan pemfokusan penelitian pada bagian ini dikarenakan pada stasiun ini terdapat kegiatan non-produktif (waste) berupa kegiatan berjalan secara overlapping dan terus menerus dari meja sablon ke area penjemuran pada saat menjemur kaos yang telah disablon. Selain itu, stasiun ini juga memiliki area (meja) penjemuran yang terbatas yang han hanya mampu menampung 34 kaos sablonan. Informasi yang diperoleh dari pemilik perusahaan bahwa rata-rata kaos yang disablon/batch adalah 100 kaos. Untuk memenuhi kekurangan tersebut, operator terpaksa menjemur kaos sablonan tersisa lainnya di area lantai, dimana operator harus melakukan penataan sedemikian rupa agar kaos sablon dapat dikeringkan dengan baik. Meskipun penataan kaos telah dilakukan dengan maksimal, sablonan tersebut masih sering terjatuh ke lantai yang mengharuskan operator melakukan penataan ulang (rework). Kegiatan penataan ulang ini, selain bersifat non-produktif, juga berimbas pada kecacatan atau penurunan kualitas sablon. Selain itu, dalam menata/menjemur hasil sablonan di lantai, operator melakukannya dengan postur tubuh yang tidak alamiah (membungkuk) yang bisa menimbulkan risiko cedera musculoskeletal.

Penelitian ini ditujukan untuk mengevaluasi proses dan metode kerja existing pada stasiun penyablonan menggunakan analisis peta kerja dan kebutuhan ruang (space requirement). Kemudian, penelitian ini mengusulkan perancangan perbaikan stasiun kerja dan perancangan fasilitas kerja usulan yang diharapkan mampu mengurangi risiko cedera musculoskeletal sekaligus menghilangkan kegiatan non produktif sehingga bisa meningkatkan produktivitas perusahaan.

\section{METODE}

Penelitian ini merupakan penelitian deskriptif berupa studi kasus. Yang menjadi objek penelitian pada studi ini adalah stasiun penyablonan yang meliputi fasilitas kerja, proses kerja dan aktivitas yang dilakukan operator pada saat melakukan kegiatan penyablonan dan penjemuran. Pengumpulan data dilakukan melalui proses observasi lapangan dan wawancara dengan pihak perusahaan. Analisis produktivitas kerja dilakukan dengan menggunakan pendekatan peta kerja dan kebutuhan ruang (space requirement) area penjemuran. Secara lengkap diagram alir metode penelitian dapat dilihat pada Gambar 1. 


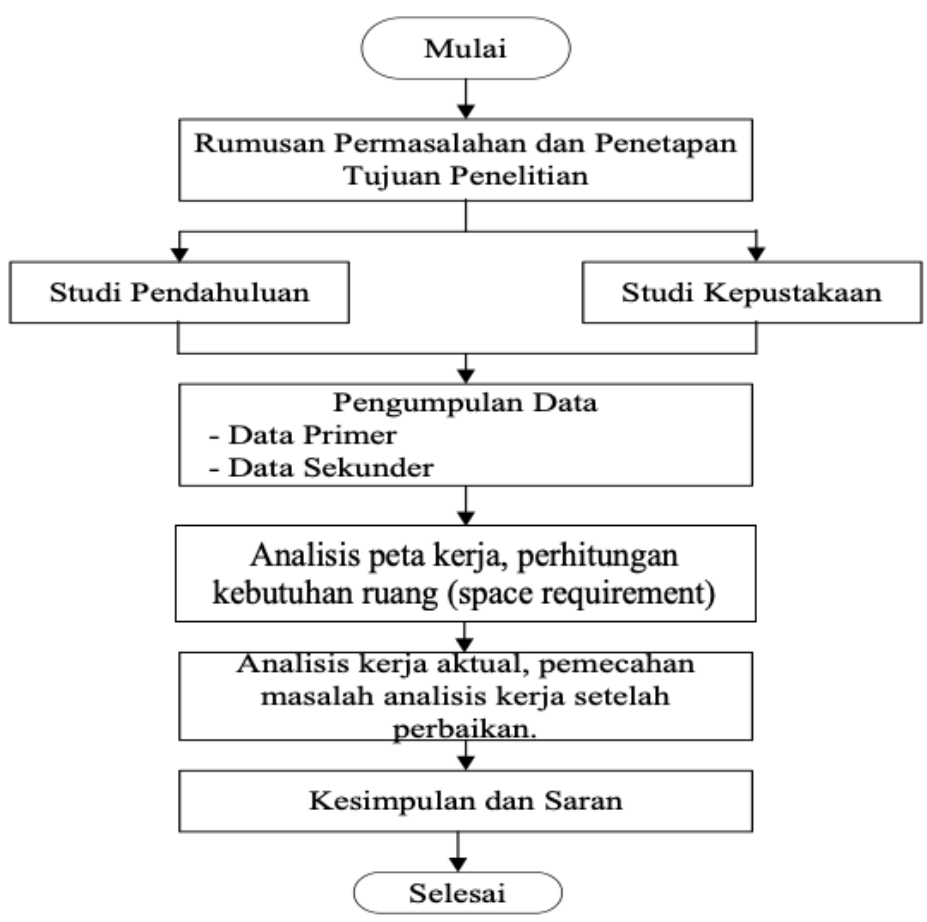

\section{Gambar 1. Flowchart penelitian}

\section{HASIL DAN PEMBAHASAN}

\section{a. Analisis peta aliran proses}

Peta aliran proses kegiatan penjemuran dapat dilihat pada Tabel 1 di bawah ini.

\section{Tabel 1. Peta Aliran Proses}

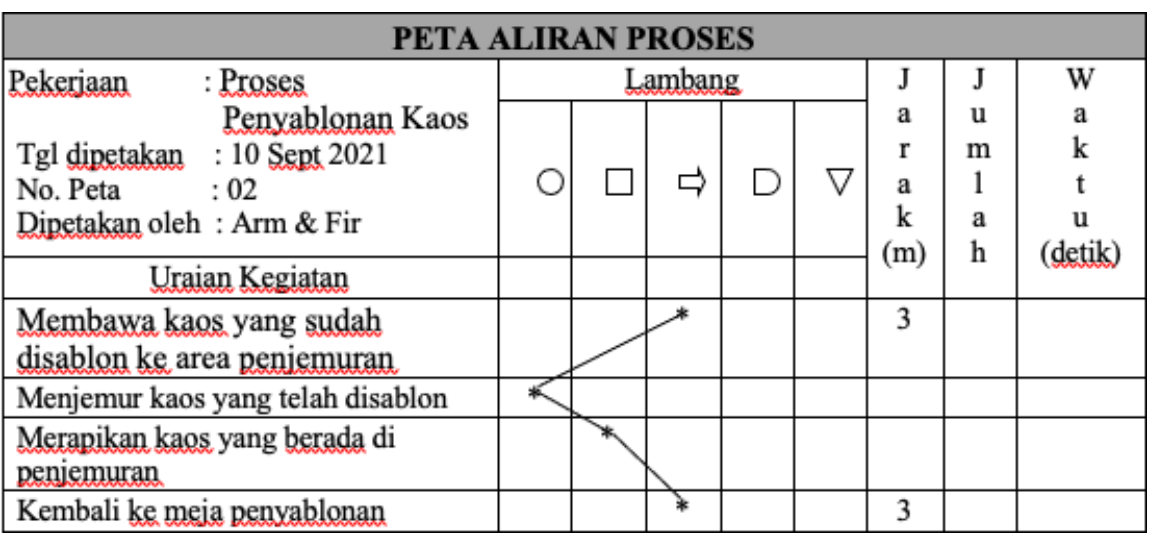

Dari Tabel 1, terlihat adanya aktivitas non-produktif, yaitu pada saat operator membawa kaos yang sudah disablon ke area penjemuran. Pekerjaan membawa kaos ke area penjemuran dan kembali ke meja sablon merupakan kegiatan yang berulang, dimana pada penjemuran berikutnya jarak yang ditempuh semakin tinggi, sehingga memerlukan waktu yang lebih lama dalam menyelesaikan pekerjaan. Selain itu, pada saat area (meja) penjemuran sudah penuh, operator terpaksa menjemur kaos di area lantai, dimana operator harus melakukan penataan sedemikian rupa agar kaos sablon dapat dikeringkan dengan baik. Meskipun penataan kaos telah dilakukan dengan maksimal, sablonan tersebut masih sering terjatuh ke lantai yang mengharuskan operator melakukan penataan ulang (rework). Kegiatan penataan ulang ini, selain bersifat non-produktif, juga berimbas pada kecacatan atau penurunan kualitas sablon. 


\section{b. Analisis peta tangan kiri dan tangan kanan}

Peta tangan kiri dan tangan kanan merupakan salah satu peta kerja setempat yang digunakan untuk menganalisa efisiensi dan efektivitas gerakan tangan manusia di dalam melakukan pekerjaan-pekerjaan yang bersifat manual (Zadry dkk, 2015). Adapun peta tangan kiri dan tangan kanan stasiun penyablonan dapat dilihat pada Tabel 2. Analisis dari peta tangan kiri dan tangan kanan tersebut memperlihatkan bahwa adanya ketidakseimbangan kerja antara tangan kiri dan kanan, dimana penggunaan tangan kanan lebih produktif daripada tangan kiri.

\section{Tabel 2. Peta tangan kiri dan tangan kanan}

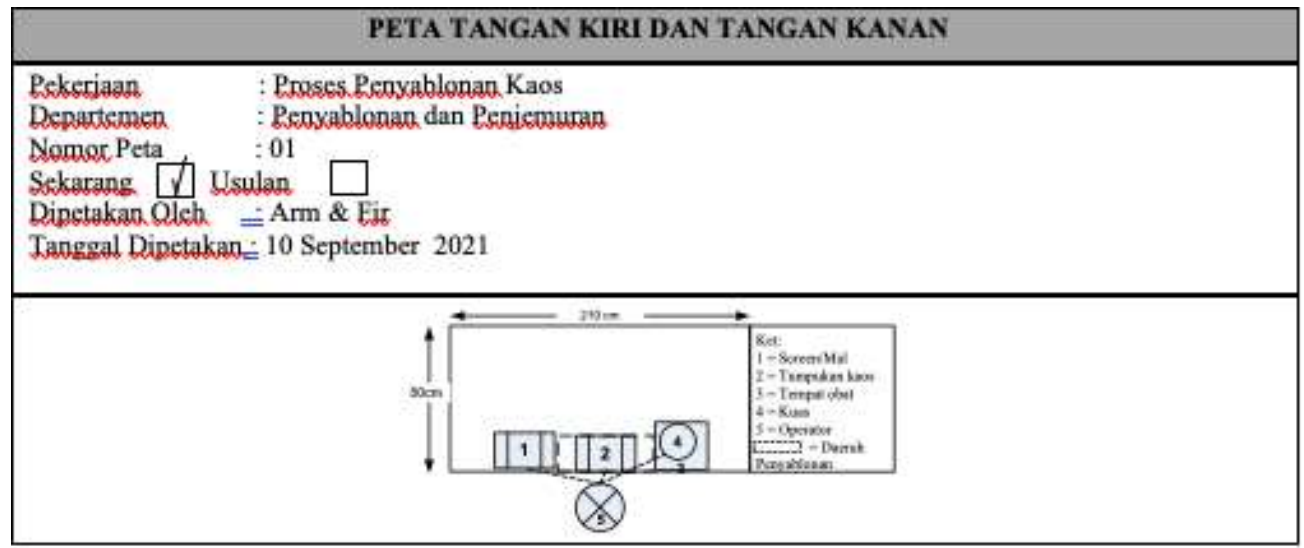

\begin{tabular}{|c|c|c|c|c|c|c|c|}
\hline Tansan Kiri & $\begin{array}{c}\text { Jarak } \\
(\mathrm{cm})\end{array}$ & $\begin{array}{l}\text { Waktu } \\
\text { (dtk) }\end{array}$ & lambans & lambans & $\begin{array}{l}\text { Waktu } \\
\text { (dtk) }\end{array}$ & $\begin{array}{l}\text { Jarak } \\
(\mathrm{cm})\end{array}$ & Tangan Kanan. \\
\hline $\begin{array}{l}\text { Meniangkau } \\
\text { screen/mal }\end{array}$ & 30 & & $\mathrm{Re}$ & - & - & - & Delay \\
\hline Memegang screen/mal & 30 & & G & - & - & - & Delay \\
\hline Membawa screen/mal & 30 & & $\mathrm{M}$ & - & - & - & Delay \\
\hline $\begin{array}{l}\text { Melctakan screen/mal } \\
\text { di atas kaos yang } \\
\text { berada di daerab. } \\
\text { penyablonan. }\end{array}$ & 5 & & RL & - & - & - & Delay \\
\hline $\begin{array}{l}\text { Mennahan screen/mal } \\
\text { agur tidak lari atau } \\
\text { berantakan }\end{array}$ & 5 & & $\mathrm{H}$ & $\operatorname{Re}$ & & 35 & $\begin{array}{l}\text { Mcpiangkau_kuss } \\
\text { yang berada di } \\
\text { atas sxadah obat } \\
\text { penvablonan }\end{array}$ \\
\hline $\begin{array}{l}\text { Menahan screen/mal } \\
\text { agar tidak. Lari atau } \\
\text { berantakan. }\end{array}$ & 5 & & $\mathrm{H}$ & G & & 35 & Memegang kuas \\
\hline $\begin{array}{l}\text { Menahan screen } / \mathrm{mal} \\
\text { agar tidak Lari atau } \\
\text { berantakan }\end{array}$ & 5 & & $\mathrm{H}$ & M & & 35 & $\begin{array}{l}\text { Mempbawa kuas } \\
\text { ks dactah } \\
\text { penyablonan }\end{array}$ \\
\hline $\begin{array}{l}\text { Menahan screen/mal } \\
\text { agur tidak _ari atau } \\
\text { berantakan. }\end{array}$ & 5 & & $\mathrm{H}$ & $\mathrm{P}$ & & 5 & $\begin{array}{l}\text { Mcngarabakan } \\
\text { kuas ke atas. } \\
\text { screen/mal }\end{array}$ \\
\hline $\begin{array}{l}\text { Menahan screen/mal } \\
\text { agar tidak. lari atau } \\
\text { berantakan. }\end{array}$ & 5 & & $\mathrm{H}$ & $\mathrm{U}$ & & 5 & $\begin{array}{l}\text { Mengolesskan } \\
\text { kuas ke dalam } \\
\text { screen/mal }\end{array}$ \\
\hline $\begin{array}{l}\text { Menahan screen/mal } \\
\text { agar tidak. Lari atau } \\
\text { berantakan }\end{array}$ & 5 & & $\mathrm{H}$ & $\mathrm{M}$ & & 35 & $\begin{array}{l}\text { Membasxa kuas } \\
\text { kembali ke dalam } \\
\text { tempat obat. }\end{array}$ \\
\hline $\begin{array}{l}\text { Menahan screen } / \mathrm{mal} \\
\text { agar tidak. Lari atau } \\
\text { berantakan. }\end{array}$ & 5 & & $\mathrm{H}$ & RL & & 35 & $\begin{array}{l}\text { Mestcpaskan kuas } \\
\text { ks dalam tempat. } \\
\text { obat. }\end{array}$ \\
\hline Memegang screen/mal & 5 & & $\mathrm{H}$ & RE & & 5 & $\begin{array}{l}\text { Menniangkau kaos } \\
\text { yang telab diolesii } \\
\text { obat. }\end{array}$ \\
\hline Memegang screen/mal & 30 & & $\mathrm{H}$ & G & & 5 & $\begin{array}{l}\text { Memegang kaos } \\
\text { yang telah diolesi } \\
\text { obat. }\end{array}$ \\
\hline Memegang screen/mal & 30 & & $\mathrm{H}$ & M & & 5 & $\begin{array}{l}\text { Membassa kaps } \\
\text { yang telah diolesi } \\
\text { ohat. }\end{array}$ \\
\hline
\end{tabular}




\section{c. Analisis kebutuhan ruang (space requirement) stasiun penjemuran}

Dalam menentukan kapasitas ruang penjemuran aktual, dilakukan dilakukan perhitungan luas total meja penjemuran keseluruhan. CV. Raya Sport memiliki 2 (dua) meja penjemuran aktual dengan dimensi masing-masing adalah $0,5 \mathrm{~m} \times 3,3 \mathrm{~m}$ dan $0,5 \mathrm{~m}$ x 6,1m. Gambaran lengkap mengenai meja penjemuran aktual dapat dilihat pada Gambar 2.

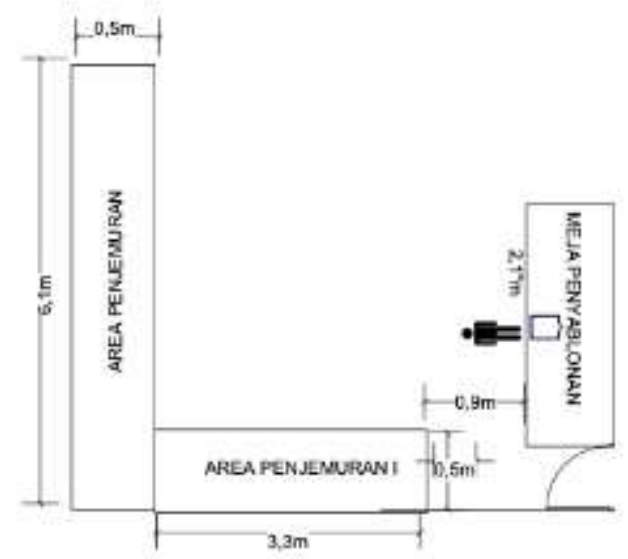

\section{Gambar 2. Meja penjemuran aktual}

Untuk menghitung luas area penjemuran keselurahan dapat dilakukan perhitungan sebagai berikut:

Luas meja penjemuran $\mathrm{I}=0,5 \times 6,1 \mathrm{~m}=3,05 \mathrm{~m}^{2}$

Luas meja penjemuran II $=0,5 \times 3,3 \mathrm{~m}=1,65 \mathrm{~m}^{2}$

Luas meja penjemuran total $=4,70 \mathrm{~m}^{2}$

Sementara itu, dalam menghitung kebutuhan area penjemuran untuk setiap kaos sablon, dapat dilakukan dengan cara menghitung luas papan alas penyablonan. Dalam hal ini, baju yang akan disablon terlebih dahulu diberikan papan alas sablon yang memiliki dimensi seperti yang terlihat pada Gambar 3.

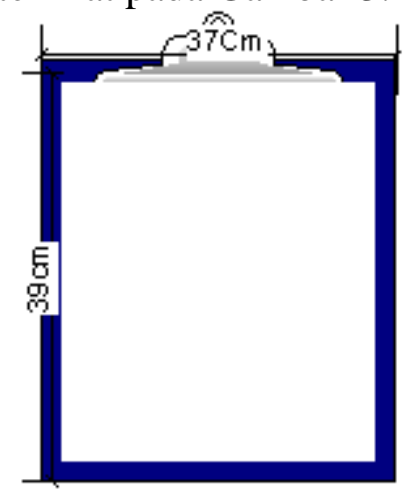

\section{Gambar 3. Papan alas penyablonan}

Perhitungan kebutuhan area penjemuran untuk setiap kaos sablon adalah dengan menghitung luas alas papan sablon dengan perhitungan sebagai berikut:

Luas = panjang alas $\mathrm{x}$ lebar alas

Luas $=39 \mathrm{~cm} \times 37 \mathrm{~cm}=1443 \mathrm{~cm}^{2} \approx 0,14 \mathrm{~m}^{2}$

Setelah diketahui luas total area penjemuran dan kebutuhan area penjemuran per setiap kaos sablon, maka perhitungan daya tampung mengikuti persamaan berikut:

Daya tampung $=\frac{\text { Luas total area penjemuran }}{\text { kebutuhan area per } 1 \text { kaos }}=\frac{4,70 \mathrm{~m}^{2}}{0.14 \mathrm{~m}^{2}}=33.57 \approx 34$ kaos 
Dari wawancara yang dilakukan dengan pemilik perusahaan, diperoleh informasi bahwa rata-rata kaos yang disablon berjumlah $100 \mathrm{kaos} /$ batch. Dengan daya tampung meja penjemuran hanya 34 kaos, maka terdapat kekurangan area penjemuran 66 kaos yang tersisa. Untuk memenuhi kekurangan tersebut, operator terpaksa menjemur kaos di area lantai, dimana operator harus melakukan penataan sedemikian rupa agar kaos sablon dapat dikeringkan dengan baik. Meskipun penataan kaos telah dilakukan dengan maksimal, sablonan tersebut masih sering terjatuh ke lantai yang mengharuskan operator melakukan penataan ulang (rework). Kegiatan penataan ulang ini, selain bersifat non-produktif, juga berimbas pada kecacatan atau penurunan kualitas sablon. Selain itu, dalam menata/menjemur hasil sablonan di lantai, operator melakukannya dengan postur tubuh yang tidak alamiah (membungkuk) yang bisa menimbulkan risiko cedera musculoskeletal (Gambar 4).

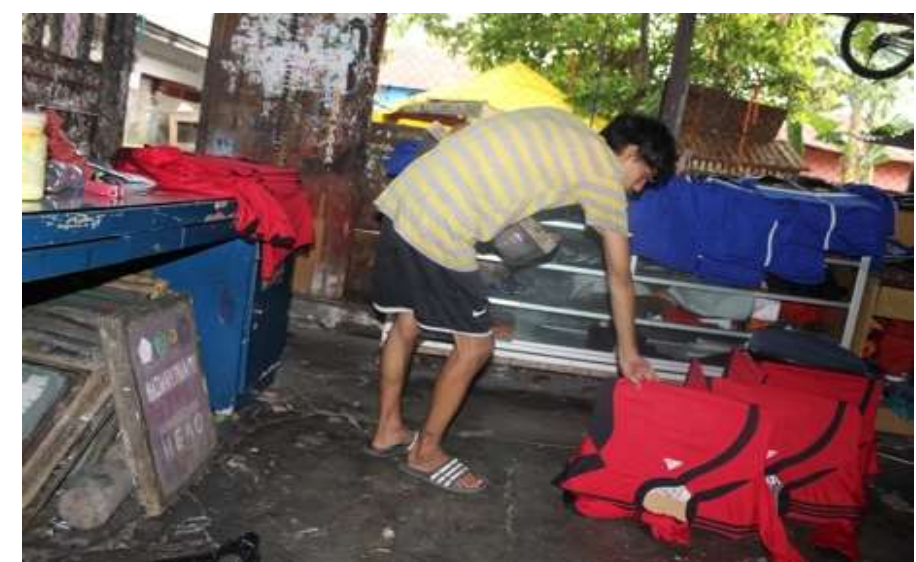

\section{Gambar 4. Aktivitas menjemur hasil sablon di lantai}

Berdasarkan pertimbangan tersebut di atas, maka diperlukan perancangan ulang fasilitas alat bantu guna meningkatkan efisiensi, efektivitas dan produktivitas operator/perusahaan. Adapun usulan fasilitas kerja yang diusulkan adalah modifikasi alas sablon dan alat penjemuran.

Alas sablon adalah alas yang terbuat dari papan tripleks yang digunakan pada tahapan penyablonan sehingga proses penyablonan berlangsung sempurna. Alas tripleks yang digunakan sama dengan yang digunakan pada sistem kerja terdahulu, namun dilakukan modifikasi berupa pemberian cantolan sebagai media penggantungan pada rel penjemuran yang bisa dilihat Gambar 5.

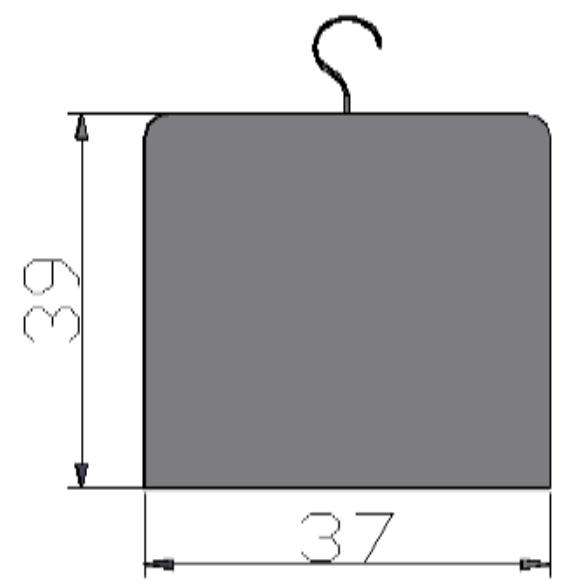

Gambar 5. Rancangan modifikasi alas sablon 
Alat bantu penjemuran merupakan fasilitas kerja penjemuran kaos hasil sablon yang terdiri dari tiang jemuran, rel penjemuran dan pengait rel. Skema usulan rancangan dapat dilihat pada Gambar 6 sampai dengan Gambar 8.

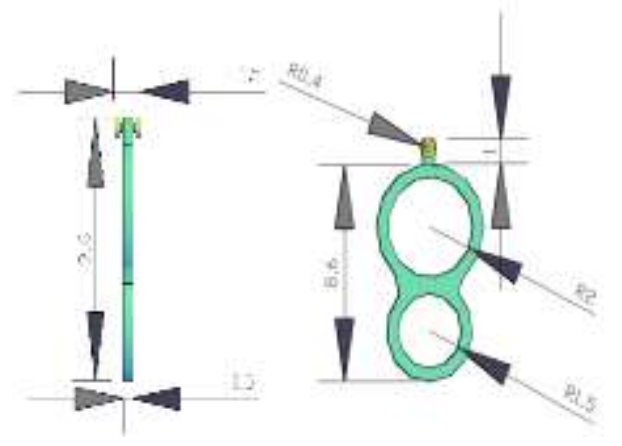

Gambar 6. Rancangan pengait rel tampak samping dan depan

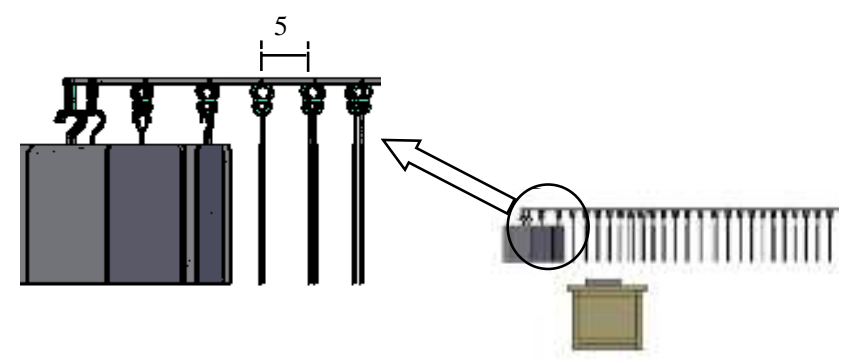

Gambar 7. Rancangan fasilitas kerja tampak samping

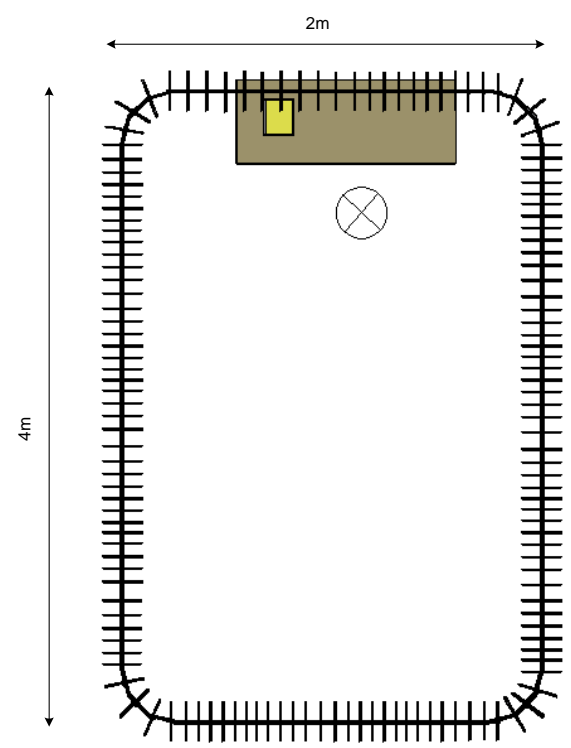

Gambar 8. Rancangan fasilitas kerja tampak atas

Pada rancangan usulan ini, setelah melakukan penyablonan, operator tidak perlu lagi berjalan ke area penjemuran, membungkuk dan menata kaos hasil sablon. Pada rancangan perbaikan ini, operator hanya perlu mengarahkan baju hasil sablon pada pengait jemuran yang bisa digeser. Secara lengkap, rancangan fasilitas kerja usulan dapat dilihat pada Gambar 9 berikut. 


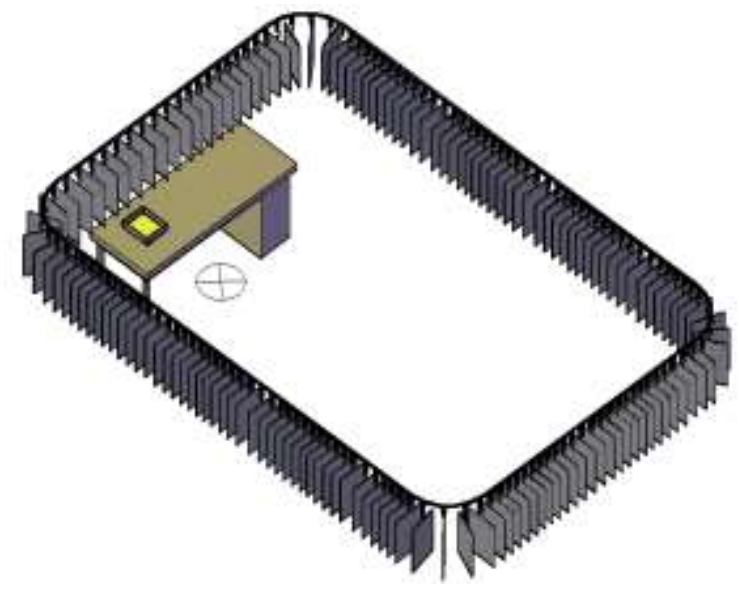

\section{Gambar 9. Rancangan fasilitas kerja tampak 3D}

Rancangan diatas mempunyai panjang rel keseluruhan $12 \mathrm{~m}$ yang disesuaikan dengan ukuran ruangan eksisting. Terdapat bantalan guna memberikan jarak antara satu gantungan (hanger) dengan gantungan yang lain. Pemberian jarak ini, dimaksudkan untuk menghindari saling menempelnya satu kaos dengan kaos yang lain yang bisa mengakibatkan kecacatan/ penurunan kualitas hasil sablon. Dengan usulan rancangan ini, kapasitas kaos yang dapat dijemur hingga 150 kaos, atau naik hampir $450 \%$ dari daya tampung awal sebanyak 34 buah kaos sablon.

Dengan menggunakan rancangan fasilitas kerja usulan, maka terjadi perubahan aktivitas kerja pada stasiun penyablonan. Adapun simulasi dari hasil perancangan fasilitas kerja penjemuran dapat dilihat pada Gambar 10 berikut :
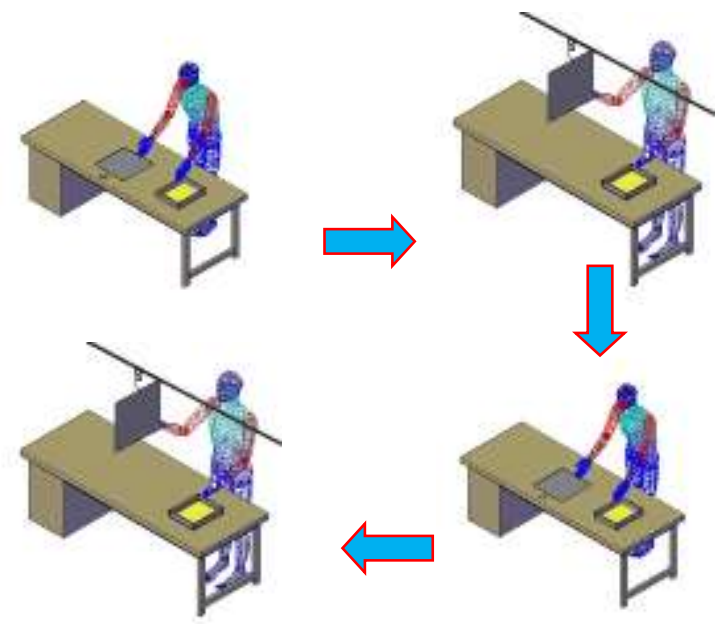

\section{Gambar 10. Simulasi hasil rancangan}

Adapun prinsip kerja dari fasilitas kerja usulan dapat dijelaskan sebagai berikut. Setelah operator melakukan proses penyablonan, maka operator tidak perlu lagi berjalan untuk menjemur kaos sablonan., melakukan penataan ulang (rework) terhadap kaos sablon yang terjatuh di lantai, serta postur yang tidak alamiah (membungkuk) pada saat menyusun/ mengeringkan kaos sablon di area lantai. Pada rancangan ini, setelah melakukan aktivitas penyablonan, operator hanya perlu menggantungkan pakaian pada pengait rel yang sudah disediakan dan menggeser rel penjemuran sehingga kaos 
berpindah ke posisi berikutnya. Hal dilakukan terus menerus sehingga semua baju selesai disablon dan dikeringkan.

Setelah dilakukan evaluasi terhadap hasil perancangan, maka terdapat perubahan antara metode kerja aktual dengan sistem kerja usulan. Pada aktivitas kerja aktual terdapat kegiatan berjalan dan membungkuk pada saat menyusun baju yang sudah disablon pada lantai. Sedangkan pada sistem kerja usulan tidak terdapat lagi aktivitas berjalan dan membungkuk. Perbandingan metode kerja aktual dan usulan dapat dilihat pada Tabel 3 berikut.

Tabel 3. Perbandingan metode kerja aktual dan usulan

\begin{tabular}{|l|l|}
\hline \multicolumn{1}{|c|}{ Metode Kerja Aktual } & \multicolumn{1}{c|}{ Metode Kerja Usulan } \\
\hline Mengambil screen & Mengambil screen \\
\hline Meletakkan dan menekan diatas kaos & Meletakkan dan menekan diatas kaos \\
\hline Mengambil kuas obat sablon & Mengambil kuas obat sablon \\
\hline Mengoleskan kedalam screen & Mengoleskan kedalam screen \\
\hline Meletakkan kuas obat & Meletakkan kuas obat \\
\hline Melepaskan screen dari kaos & Melepaskan screen dari kaos \\
\hline Mengangkat kaos & $\begin{array}{l}\text { Menggantungkan kaos ke rel } \\
\text { penjemuran }\end{array}$ \\
\hline Membawa ketempat penjemuran & $\begin{array}{l}\text { Menggeser rel penjemuran hingga } \\
\text { berpindah ke posisi berikutnya }\end{array}$ \\
\hline Menyusun di tempat penjemuran & - \\
\hline Kembali ke meja penyablonan & - \\
\hline
\end{tabular}

Ditinjau dari waktu penyelesaian proses, dengan menggunakan rancangan baru maka akan menghilangkan beberapa kegiatan non produktif, sehingga waktu penyelesaiannya menjadi lebih singkat.

\section{SIMPULAN}

Kesimpulan dari penelitian ini bahwa usulan perbaikan kerja pada stasiun penyablonan CV. Raya Sport adalah dengan mengusulkan perancangan alat bantu penjemuran dan modifikasi papan alas sablon. Adanya alat bantu ini mampu menghilangkan aktivitas aktivitas non-produktif seperti kegiatan berjalan dan menata ulang (rework) yang berkontribusi pada peningkatan produktivitas. Usulan alat bantu penjemuran juga memberikan kontribusi pada peningkatan kapasitas daya tampung area penjemuran, dari semula hanya mampu menampung $34 \mathrm{kaos} / \mathrm{batch}$ menjadi $150 \mathrm{kaos} / \mathrm{batch}$.

Untuk penelitian berikutnya disarankan membahas aspek teknis yang lebih detail dari usulan rancangan yang diberikan, serta menambah perhitungan aspek ekonomi dan keuangan sehingga usulan perancangan alat bantu penjemuran dapat diterapkan pada perusahaan.

\section{DAFTAR PUSTAKA}

Indrajaya, D. (2019). Produktivitas Total ditinjau dari Segi Pembelian Material dan Penjualan Produk di PT Yanmar Diesel Indonesia. Factor Exacta. 12(2). Hal. 94 - 100.

Rosa, E.S. (2003). Analisis Manajemen Strategi PD. Kecap Zebra Dalam Menghadapi Persaingan Yang Semakin Kompetitif. IPB, Bogor.

Supriyanto, A. (2015). Pengaruh Sikap Kerja 5S (Seiri, Seiton, Seiso, Seiketsu, Shitsuke) Terhadap Produktivitas. Riset dan Manajemen Akuntansi. 5(9). Hal. 23 - 31. 
Wahyono. (2006) Usaha Peningkatan Produktivitas Kerja Sumber Daya Manusia. Infokam. 2(1). Hal.1-6

Zadry, H.R., Susanti, L., Yuliandra, B., Jumeno, D. (2015). Analisis dan Perancangan Sistem Kerja. Andalas University Press, Padang. 